\title{
An Evaluation of Top Notch Fundamentals B: A Four Phase Study
}

\author{
Marzie Ahmadi \\ Sheikhbahaee University, Iran \\ E-mail: Nazaninahmadi703@yahoo.com
}

Doi:10.7575/aiac.alls.v.7n.1p.242
URL: http://dx.doi.org/10.7575/aiac.alls.v.7n.1p.242

Received: 04/10/2015

Accepted: 22/12/2015

\begin{abstract}
Textbooks play an important role in educational contexts especially in EFL contexts their role are more highlighted. Textbook evaluation in any type, predictive or retrospective, is a necessary part of curriculum design and in this sense is a worthwhile means of conducting research. Recently, Top Notch series have become widely used in Iranian English Institutes and in high schools and pre-university schools. Thus, this study aimed to evaluate Top Notch Fundamentals B based on first, authors' objectives, and second, the cultural content of the book based on the framework proposed by Ferit Kilickaya (2004). Thirdly, the universal characteristics of EFL materials proposed by Ansari and Babaii was used to see to what extent the book matches those characteristics. The amount and type(s) of technological use was also examined. The strengths and some drawbacks of the book for EFL setting use were also mentioned in the study. The findings would be beneficial for teachers and material developers in EFL contexts.
\end{abstract}

Keywords: Material, material evaluation, Top Notch Fundamentals B, Ferit Kilickaya framework, Ansari and Babaii framework, technological use, authors' claims

\section{Introduction}

Language-learning materials can refer to "anything which is used by teachers and learners to facilitate the learning of a language" (Tomlinson, 1998, p. 2). Although these facilities are various, "most people associate language-learning materials with course books because that has been their main experience of using materials" (Tomlinson, 1998, p. 2). The materials to be selected by a teacher is one part of the course designed and should reflect the goals of the course (Macalister \& Nation, 2010). Teachers inevitably face a plethora of materials available in each time in the market, and this arises the need for them to judge which materials fit their purposes. As Sheldon (1988) puts it choosing a particular material shows the underlying executive educational decision in which there is a significant professional, financial, and even political investment. Saphir and Gower (1997) (cited in Haldeman, 2008) stated that "many things are important for good schools: curriculum...parent involvement...a clean, safe building..., but of all the things that are important... nothing is as important as the textbook and materials" (p. 15).

Having completed the needs analysis and course design steps by the teacher, to execute the results obtained, the teacher finds him/herself in the position to turn these findings into actual materials. Three possible ways are selecting from existing materials (materials evaluation), writing your own materials (materials development), and modify existing materials (materials adaptation) (Hutchinson \& Waters 1987). This type of evaluation which is aimed at finding appropriate materials to fit the course needs and objectives is not the only possible way. According to Rod Ellis (1997) materials evaluation has two types: predictive and retrospective. A brief review of the literature relating to materials evaluation shows that most of the researches conducted so far have focused on the predictive evaluation to make a decision regarding what materials to use. Whereas, in the other type which is also the method of evaluation in the present study, the material is examined to find the weaknesses and the strengths of it. This retrospective evaluation can serve "as a means of testing the validity of a predictive evaluation, and may point to ways in which the predictive instruments can be improved for future use" (Ellis, 1997, p. 37).

This high profile means that in all of the possible ways of materials preparation the unescapable process of evaluation is a preliminary; so to make this process possible, the definition and adaptation of systematic criteria for assessing course books are vital. To this end, there are numerous schemes and checklists that have been offered by scholars which have many similarities. Another way which the present study has selected to evaluate the Top Notch Fundamentals B of ELT materials, is using the author/s claims as the checklist. Based on the aforementioned facts, choosing materials and especially textbooks in our concern has always been an overwhelming matter for both teachers and learners.

\section{Review of the literature}

It is claimed that material evaluation is a dynamic and subjective process with no definitive yardstick; besides, the criteria and the key questions central for setting up a material evaluation scheme to some extent depends on the changing fashions in linguistics field (Sheldon, 1988). Nevertheless, evaluation is an inseparable part of educational 
process and needs to be done to serve as a means of textbook improvement and modification. There is a vast body of literature on material evaluation, some of which will be presented.

In the first camp, there are studies done to highlight the role of textbooks in English language teaching. Many roles have been attached to the textbooks among which are considering textbooks as the most preferred instructional material in English language teaching, enabling teachers to achieve aims and objectives set based on learners' needs, and conveying the knowledge to the learners (Cunningsworth, 1995). To add further dimensions to the role of textbooks, the studies were conducted by Hutchinson and Torres (1994) and Allwright (1981), their findings were reported as such textbooks provide the necessary input into the classroom lesson through different activities, readings and other parts of a lesson; and enhancing the opportunity to learn by characterizing the lesson as an interaction between teacher, learners, and material. Textbooks are also a reference source on grammar, vocabulary, and pronunciation for learners; in addition to serving as a syllabus and a self-study source.

The next step after appreciating the role/s textbooks play in the English language teaching is to find an evaluative checklist on which the assessment of the material is going to be based. It can be based on physical characteristics of textbooks such as layout, organizational and logistical characteristics, methodology, aims, approaches, and the degree to which a set of material is not only teachable but also fits the needs of the individual teacher's approach as well as the organization's overall curriculum (Brown, 1995; Cunningsworth, 1995; Sheldon, 1988; Williams, 1983).Many other checklists have been presented by scholars with more or less the same criteria for evaluating the textbooks (Fetsko, 1992; Miekley, 2005; Skierso, 1991; Stradling, 2001).

To make sure that the language textbooks selected based on available checklists are suitable for the particular EFL instructional setting, many other different aspects need to be taken into account. For instance the age of the learners, their level of proficiency, their cultural background, their social class, whether their L1s are homogeneous, their attitude toward the target language (English) and so on. Consequently, it calls for a thorough examination of the textbooks that many studies to date have addressed this issue regarding available English textbooks which are used in Iran. Kayapinar (2009) in his analysis of two textbook packages, namely, Opportunities and New English file, pointed out that there is not an overall positive view toward mentioned books among teachers and the books do not satisfy learners' needs and interest. In another study by Azizifar, Koosha, and Lotfi (2010) two series of ELT textbooks used in Iranian high schools by the Ministry of education were evaluated. They suggested that in the textbooks, there should be enough opportunity for the learners to practice the language they are learning communicatively.

Moreover, Sahargrad, Rahimi, and Zaremoayyeri (2008) set the study to find the strength and weaknesses of Interchange third edition. Iranian senior high school and pre-university English textbooks, also, went under evaluation by Mosallanejad and Riazi (2010) to investigate the types of learning objectives represented in them. The study was based on Bloom's (1956) taxonomy and the results showed that in all grades the lower-order cognitive skills were more prevalent than the higher-order ones. Furthermore, the difference between the senior high school and pre-university textbooks in terms of the level of taxonomy were significant insofar as the pre-university textbook used some of higherorder learning objectives.

Last but not least, to the best of the researcher's knowledge, the studies that have been conducted related to the evaluation of Top Notch series in EFL teaching settings are as follows. A study was conducted on the evaluation of Top Notch Series by Akbari Kelishadi and Sharifzade (2013) using Littlejohn's (1998) framework. Their objectives were to find whether the series fulfilled the intended objectives and encouraged learners to communicate successfully by offering opportunities for interaction. In a similar vein, Eslami Rasekh, Esmaeli, Ghavaminia, and Rajabi (2010) set out to evaluate the four mostly instructed courses in Iran English language institutes. The books were Top Notch, Interchange, Headway, and On Your Mark. The researchers evaluated the course books under study in 2 stages based on Mcdounough and Shawes (2003) division of course book evaluation into internal and external evaluation. After a thorough examination of introduction and table of contents, and in-depth examination of the cover page and introductory sections of the books, they concluded that Top Notch best meets Mcdounough and Shaw s (2003) evaluation criteria.

The present study aims to examine the Top Notch Fundamentals B based on its authors' claims and whether the objectives of the authors are realized via the content of the book, on what theoretical basis their claims are based, the pedagogical values the content has, and the learning benefits on the part of language learners. The cultural points presented in the book and the kind and amount of technology use are also going to be investigated. The following research questions are addressed:

1. To what extent is Top Notch Fundamentals B's content able to fulfill the objectives claimed by its authors?

2. What cultural and technological features does Top Notch Fundamentals B have?

3. To what extent does the content of Top Notch Fundamentals B match the universal characteristics of EFL materials?

4. What are the strengths and weaknesses of the Top Notch Fundamentals B?

\section{Methodology}

\subsection{Materials}

The book selected for the purpose of this study was Top Notch Fundamentals B from Top Notch Series (Ascher \& Saslow, 2011). The series consisted of six-level communicative English course with two beginning entry levels namely Fundamentals A and Fundamentals B for adults and young adults. Totally speaking, the Top Notch series included 12 
textbooks, written by Joan Saslow and Allen Ascher in 2006 and published in the United States of America by Pearson Longman Incorporation. Top Notch Fundamentals B consisted of seven units, each of which contained three lessens. Each two-page lesson began with a clearly stated communicative goal and ended with controlled or free communication practice. Each lesson provided vocabulary, grammar, and social language contextualized in all four skills.

In order to ensure students' solid acquisition of vocabulary essential for communication, Top Notch contained explicit presentation, practice, and systematic extended recycling of words, collocations, and expressions appropriate at each level of study. The extensive captioned illustrations, photos, definitions, examples, and contextualized sentences removed doubts about meaning and provided a permanent in-book reference for student test preparation. An added benefit was that teachers did not have to search for pictures to bring to class and did not have to resort to translating vocabulary into the students' native language.

Grammar was approached explicitly and cognitively, through form, meaning, and use. Top Notch was designed for international communication and set a new standard using the natural language that people really speak. The book also prepared students for interaction with both native and non-native speakers of English, both linguistically and culturally. English was treated as an international language, rather than the language of a particular country or region. In addition, Top Notch helped students develop a cultural fluency by creating an awareness of the varied rules across cultures for: politeness, greetings and introductions, appropriateness of dress in different settings, conversation do's and taboos, table manners, and other similar issues.

It was claimed by the writers of the book that Top Notch would prepare students to interact successfully and confidently with both native and non-native speakers of English and would bring students to a "Top Notch" level of communicative competence (Ascher \& Saslow, 2006). The book was designed to serve the needs of language learners in EFL settings, because its authors believed that the materials designed for ESL settings have not been appropriate for EFL settings with the classroom input as the only source of learners' exposure to L2 input. Top Notch made use of corpora and the analysis and inclusion of conversation strategies. Top Notch was a corpus-informed course backed by the extensive database of the Longman Corpus Network, and it used both the Longman Spoken Corpus as well as the Learners' Corpus of Common Learner errors. In addition, Top Notch was also based on use of a broader, more informal corpus of spoken and written language including authentic interviews, real conversations, and authentic texts to ensure that conversation strategies were well understood and applied.

It was commonly accepted that conversation strategies must be part of a spoken syllabus - strategies such as ways to keep a conversation going, ways to soften conflict, etc. The mastery of conversation strategies was one aspect of empowerment. The authors of the book believed that building conversation strategies into practical conversation models for productive manipulation and personalization would provide students the social confidence to communicate with others in a new language. Regarding the use of technology, the book's Super CD-ROM included a variety of exciting interactive activities: Speaking practice, Interactive Workbook, Games and Puzzles, and Top Notch karaoke. The disk could also be played on an audio CD player to listen to the Conversation Models and Top Notch songs. There was also a complete assessment package with exam view software including achievement tests which assess listening, vocabulary, grammar, and writing. Two review tests provided additional cumulative assessment. A lively and entertaining video offered a TV-style situation comedy that reintroduced language from each Top Notch unit, plus authentic unrehearsed interviews with English speakers from around the world.

\subsection{Instrumentation and data analysis}

Three lessons of the Top Notch Fundamentals B were selected and analyzed based on the, first, the claims of the authors mentioned in the preface of the book. Learning theory(s) on which the content of the book and the way of its presentation were based, were also investigated. To this end the categorization made by Säljö was used in which five categories was identified namely: the behaviorist orientation to learning, the cognitive orientation to learning, the humanistic orientation to learning, the social/situational orientation to learning.

To evaluate the cultural content of the book the framework presented by Ferit Kilickaya (2004) was adopted which included fifteen questions (Appendix 1). And to see to what extent the anatomy of the less fits the proposed universal characteristics of EFL lessons Ansari and Babaii (2002) framework was used. The characteristics were as follows: 1.objectives explicitly laid out in an introduction, and implemented in the material, 2. good vocabulary explanation and practice, 3. periodic review and test sections, 4. appropriate visual materials available, 5. interesting topics and tasks, 6. clear instruction, 7. plenty of authentic language, 8. clear attractive layout, print easy to read, 9. content clearly organized and graded, 10. good grammar presentation and practice.

\section{Results}

The thorough examination of selected lessons of Top Notch Fundamentals B reveals that more than half of the tasks demand language learners to respond, which is in line with the claim of the authors that the book encourages language learners to use the language and be active communicators via participating in classroom activities. The vocabulary part is presented with accompanying pictures to clarify the meaning of them and provide for learners new words related to the topic of the lesson to empower them to comprehend the followed conversations and to successfully complete the guided practices of the lesson. Grammar points which are necessary for learners to know in order to be able to communicate successfully when the selected topic of the lesson is raised, are presented in the box after the vocabulary part. Charts provide examples and paradigms enhanced by simple usage notes at students' level of comprehension. This takes the guesswork out of meaning, makes lesson preparation easier for teachers, and provides students with 
comprehensible charts for permanent reference and test preparation. All presentations of grammar are followed by exercises to ensure adequate practice. An example of the grammar box is presented below:

GRAMMAR. Can and can't

To talk about ability, use can or can't and the base form of the verb.

She can play the guitar.

Questions

Can you play the guitar?

Can he speak English?

Can not
He can't cook.

Short answers

Yes, I can. / No, I can't.

Yes, he can. / No, he can't.

can't

The lessons' format match the universal characteristics of EFL lessons proposed by Ansari and Babaii (2002) and smooth flow of the exercises from controlled to free ones enable learners to feel their progression at the end of each lesson in the wrap up section. Language learners are supposed to make the learned language their own in wrap up part when they are to use four skills of listening, speaking, reading, and writing to do the pair works assigned. The book's cultural content evaluation based on the framework proposed by Ferit Kilickaya (2004) revealed that a variety of cultures are addressed and there is no bias toward a specific culture. For instance, in lesson one in vocabulary part there is a picture of a woman putting on makeup and in the exercise accompanying the grammar box a sentence with a blank space to fill with this verb says: "When my wife is late for work, she..........on her make up on the train". Although putting up makeup in public or even speaking freely about it is regarded taboo in Iran, as an instance of EFL setting, the learners will be informed about cross cultural differences.

The cultural points are presented in a neutral position without any comment as being good or bad on the given information. Some of the cultural points are presented here. Different dress codes are illustrated in pictures accompanying new vocabulary and conversations in each lesson. In lesson two "Ask about people's activity", the Mike and Patty's activities in a typical day are presented. Patty reads newspaper while eating breakfast and Mike prepares breakfast when Patty is taking a shower. Their pet sleeps on their bed and is around when they are doing their household chores. In lesson three "Discuss Plans", the common activities people mostly do on the weekends are mentioned. Among them are exercising and going to movies, the point of difference is that people in other countries may have different options and preferences. As an example in Iranian culture catch up with their week's activities is what people commonly do on weekends. It can be concluded that Top Notch is considerate of diversity in the sociocultural identities it presented and provides information about the values of different cultures and the customs and traditions of various nations it tried to set the bases of interculturality within its audience.

Nearly all parts of each lesson have audios which provide learners the facility of listening to the lesson repeatedly whenever they wish and in a deliberate pace. A companion website as www.longman.com/topnotch provides numerous additional resources for students and teachers without any cost. There is also the audio program containing listening comprehension activities, rhythm and intonation practice, and targeted pronunciation activities that focus on accurate and comprehensible pronunciation. A variety of native and non-native speakers are included in conversations and other recorded parts.

The topics chosen for the lessons and the conversation models feature the language people use in reality. In this sense, the book exposes learners to authentic language and the language specific realizations of speech acts improves learners' pragmatic competence. Two conversation models are presented here, one about how to make a polite phone call and the other about how to discuss plans. They make the learners aware of the appropriate use of the language which helps them not to face communication breakdowns when communicating with native speakers.

\section{Make a polite phone call}

Jan: Hello?

Laura: Hi, Jan. This is Laura. What are you doing?

Jan: I'm feeding the kids.

Laura: Should I call you back later?

Jan: yes, thanks. Talk to you later. Bye.

Laura: Bye.

\section{Discuss plans}

Scott: So what are you doing this week?

Dan: I'm not sure. What about you?

Scott: Well, on Saturday, if the weather is good, I'm meeting Pam in the park.

Dan: Do you want to get together on Sunday? I'm not doing anything special.

Scott: Sure. Call me Sunday morning. 


\section{Discussion and Conclusion}

In line with what Cunningsworth (1995) stated as one of the roles of textbooks in English language teaching, the analysis of the three lessons selected from Top Notch Fundamentals B demonstrates that the claims of the authors are met in most parts of the content. Except that, the authors claim that the book provides authentic language for both teachers and learners. This arise from the attempt of collecting corpus-informed data for developing Top Notch series. The Longman Spoken Corpus, the Learners' Corpus of Common Learner Errors, and informal corpus of spoken and written language like interviews and real conversations and authentic texts are the sources. Nevertheless, authenticity is a topic over which a lot of debate has been arose to date. As Richards (2005) argues in his paper the aim of people using authentic language differs with that of language learners in classroom setting and as soon as the language is decontextualized from its context, it is not authentic anymore.

As the results of the study revealed, to reach the objective of developing learners' communicative competence, Top Notch has been succeeded. This achievement is considered a privilege for the book series because the vitality of developing learners' communicative competence is a consequence of recent swings in linguistics which as Sheldon (1998) stated, affect all materials evaluation. The pair works and the exercises which encourages learners to use language and participate in classroom activities rather than being passive receivers serve to this end. This is what Hutchinson and Torres (1994) and Allwright (1981) also found in their studies as one of the roles of textbooks in providing the opportunity of interaction between learners, teachers, and material to enhance students' learning. In cases of vocabulary and grammar presentation, as the results shows the focus is on both form and meaning to enable learners not just recognizing the form, but also learning to do meaningful tasks which follows the task principle: activities in which language is used for carrying out meaningful tasks promote learning (Johnson 1982). In addition, the vocabulary and grammar provide the suitable source for learners (Cunningsworth, 1995), and they prove useful in successful completing the related exercises.

In the case of cultural points which are presented in the lessons to develop learners' intercultural competence, the book acts like a provider of necessary input for learners. This is one of the roles Hutchinson and Torres (1994) consider for instructional material in EFL/ESL settings. Finally, it can be concluded that Top Notch Fundamentals B satisfies authors' claims and objectives by developing learners' competences as components of communicative competence. The vocabulary, grammar, and topics chosen in a way that were tangible for EFL learners in the perceived level of proficiency and at the same time were those native speakers use in real life. The simultaneous focus on form, meaning, and use in all the parts of the lessons enabled learners to develop their linguistic and pragmatic competence.

This rich source of input can be pedagogically helpful for both teachers and learners even for those without access to additional input via internet or other sources. That is a suitable way of presenting material for any EFL setting like what is the situation in Iran in which English is considered a foreign language with the classroom and course book as the only source of input for most of the language learners. Although the book is in most cases advantageous, it may need to be adapted in some parts due to the different learners that the teacher encounter in the classroom regarding their ages, level of proficiency, background information, and needs.

\section{Limitations and suggestions for further research}

The study was limited in the sense that there was no access to teachers teaching this book in EFL classrooms to access their attitudes toward the strength and weaknesses of the book in achieving its claimed objective in real situation of the classroom. The study can be conducted in EFL classroom settings to see which activities and tasks of the book are/are not in line with the needs of EFL learners in specific settings.

\section{References}

Akbari Kelishadi, A. \& Sharifzadeh, A. (2013). An evaluation of Top Notch series. International Journal of Language Learning and Applied Linguistics World. 4(4), 60-73.

Allwright, R. L. (1981). What do we want Teaching Material for? ELT Journal, 36(1), 5-13.

Ascher, A., \& Saslow, J. (2011). Top Notch Series. Longman: Pearson Education.

Azizifar, A., Koosha, M., \& Lotfi, A. R. (2010). An analytical evaluation of Iranian high school ELT textbooks from 1970 to the present. Procedia Social and Behavioral Sciences, 3, 36-44.

Brown, J. D. (1995). The Elements of Language Curriculum. New York: Heinle Publishers.

Cunningsworth, A. (1995). Choosing your Coursebook Oxford: Heinemann Publishers Ltd.

Ellis, R. (1997). The empirical evaluation of language teaching materials. ELT Journal, 51(1), 36-42. http://dx.doi.org/10.1093/elt/51.1.36

Eslami Rasekh, A., Esmaeli, S., Ghavamnia, M., \& Rajabi, S. (2010). Don't judge a book by its cover. Textbook evaluation in the EFL setting. The Journal of International Social Research, 3(14), 448-461.

Kilickaya, F. (2004). Authentic materials and cultural content in EFL classrooms. The Internet

TESL Journal. X(7).

Fetsko, W. (1992). Approaching Textbook Selection Systematically in Herlihy, J. G. (Ed.). the Textbook

Controversy-Issues, Aspect, Perspective. New Jersey, Norwood. 
Haldeman, M. (2008). The new teacher's guide to success: A personalized planning guide for teachers. Shell Education Publication.

Hutchinson, T \& Torres, E. (1994). The Textbook as an Agent of Change. ELT Journal, 48(4).

Hutchinson, T. \& Waters, A. (1987). English for Specific Purposes. New York: Cambridge University Press.

Hutchinson. T. (1987). What is underneath? An interactive view of the materials evaluation. In L. E. Sheldon (ed.), ELT textbooks and materials: Problems in evaluation and development, (pp. 37-44), Oxford: Modern English Publications.

Jahangard, A. (2007). The evaluation of the EFL materials taught at Iranian public high schools Karen's Linguistics Issues. Retrieved October 15, 2011, from http://www3.telus.net/linguisticsissues/bymonth.html.

Kayapinar, U. (2009). Coursebook evaluation by English teachers. Inonu University Journal of the Faculty of Education, (10), 69-78.

Kilickaya, F. (2004). Guidelines to Evaluate Cultural Content in Textbooks. The Internet TESL Journal, X (12). Retrieved from: http://iteslj.org/Techniques/Kilickaya-CulturalContent/.

Littlejohn, A. (1998). The analysis of language teaching materials: Inside the Trojan horse. In B. Tomlinson

(Ed.), materials Development in Language Teaching, 190-216. Cambridge: Cambridge University Press.

McDonough,J. \& Shaw, C. (2003). Materials and methods in ELT: A teacher's guide. (2 ${ }^{\text {nd }}$ Ed). Malden, MA: Blackwell Publishing Ltd.

Miekley, J. (2005). ESL textbook evaluation checklist. The Reading Matrix, 5(2).

Nation, I.S.P. \& Macalister, J. (2010). Language Curriculum Design. New York: Routledge.

Riazi, A. M., \& Mosallanejad, N. (2010). Evaluation of learning objectives in Iranian high-school and pre-university English textbooks using Bloom's taxonomy. TESL-EJ Electronic Journal for English as a Second Language, 13(4).

Richards, J. C. (2005). The role of Textbooks in a language program. Cambridge: Cambridge University Press.

Richards, J. C. (2006). Materials Development and Research: Making the Connection. Regional Language Center Journal, 37 (1), 5-26.

Sahargard, R., Rahimi, A., \& Zaremoayeddi, I. (2008). An in-depth evaluation of interchange series (3 ${ }^{\text {rd }}$ ED.). Porta Linguarum, 12(1), 37-54.

Sheldon, L. E. (1988). Evaluating ELT textbooks and materials. ELT Journal, 42(4), 237-246.

Skierso, A. (1991). Textbook Selection and Evaluation. In M. Celce-Murcia (Ed.), Teaching English as a second or foreign language, 432-453. Boston: Heinle and Heinle Publishers.

Straddling, R. (2001). Teaching $20^{\text {th }}$-century European history. Strasbourg, Council of Europe Publishing.

Tomlinson, B. (1998). Materials Development in Language Teaching. Cambridge University Press.

Ur, Penny (1996). A Course in language teaching-practice and theory. Cambridge: Cambridge University Press.

Williams, D. (1983). Developing Criteria for Textbook Evaluation. ELT Journal, 37(3), 251-255.

\section{Appendix 1}

Guidelines to evaluate a textbook for cultural information:

1. Does the book give any information, instructions or suggestions about how the book may be used and how the cultural content may be handled?

2. Does the book address specific learners or are there any characteristics of the learners that the book addresses to?

3. Does the book suggest any role that the teachers using it should have?

4. Do they include a variety of cultures or just specific ones such as British or American culture?

5. Do they represent the reality about the target culture or the author's view?

6. Where is the cultural information taken from? Author's own ideas or empirical research?

7. What subjects do they cover? Are these specific to the target culture? Are there any topics that might not be culturally suitable for the learners in class?

8. What cultural and social groups are represented? Is this adequate coverage of a variety of people or is this limited to a chosen people? If so, what kind of people are these? Are there any stereotypes?

9. Does the book include generalizations about the culture? Does it inform the audience of the fact that what is true of the parts is not necessarily true of the parts?

10. Is the cultural information presented with comments such as being good or being bad? Or is it presented without such comments?

11. Are there illustrations? If so, are these appropriate to the learners' native culture? Would additional information be necessary to explain them or are they self-explanatory?

12. What are the activities asked of the learners? Are they familiar to the learners?

13. Would a teacher using this book need specialized training to be able to use it or is there enough information given?

14. What are the learners supposed to do with the cultural information such as using actively or just be aware of it for a better understanding of the target culture?

15 . What is your overall view of the textbook? 